\title{
Modeling of the Density of States in Field-Effect Zinc Oxide Semiconductor Devices Fabricated by Ultrasonic Spray Pyrolysis on Plastic Substrates ${ }^{\dagger}$
}

\author{
Ovier Obregon ${ }^{1, *}$, David Barba ${ }^{2}$ and Miguel A. Dominguez ${ }^{1}$
}

1 Centro de Investigaciones en Dispositivos Semiconductores, Instituto de Ciencias, Benemérita Universidad Autónoma de Puebla (BUAP), Puebla 72570, Mexico; miguel.dominguezj@correo.buap.mx

2 Institut National de la Recherche Scientifique (INRS), Varennes, QC J3X 1S2, Canada; David.Barba@inrs.ca

* Correspondence: ovier.mectronica@gmail.com

+ Presented at the 1st International Conference on Micromachines and Applications, 15-30 April 2021; Available online: https://sciforum.net/conference/Micromachines2021.

Citation: Obregon, O.; Barba, D.; Dominguez, M.A. Modeling of the Density of States in Field-Effect Zinc Oxide Semiconductor Devices Fabricated by Ultrasonic Spray Pyrolysis on Plastic Substrates. Eng. Proc. 2021, 4, 12. https://doi.org/ 10.3390/Micromachines2021-09552

Academic Editor: Ion Stiharu

Published: 14 April 2021

Publisher's Note: MDPI stays neutral with regard to jurisdictional claims in published maps and institutional affiliations.

Copyright: (C) 2021 by the authors. Licensee MDPI, Basel, Switzerland. This article is an open access article distributed under the terms and conditions of the Creative Commons Attribution (CC BY) license (http://creativecommons.org/licenses/by/4.0/).

\begin{abstract}
In this work, using a physically based simulator, the modeling of the density of states (DOS) through the fitting of the electrical characteristics in field-effect devices is presented. The transfer characteristic of zinc oxide $(\mathrm{ZnO})$ thin-film transistors is simulated, along with the capacitance-voltage curves in metal-insulator-semiconductor capacitors using $\mathrm{ZnO}$ as an active layer. The $\mathrm{ZnO}$ semiconductor devices were fabricated by high-frequency ultrasonic spray pyrolysis on polyethylene terephthalate plastic substrates. Different aspects were considered and discussed to model the device interfaces.
\end{abstract}

Keywords: density of states; ZnO; spray pyrolysis; TFTs; MIS capacitor

\section{Introduction}

Metal-oxide semiconductors have received considerable attention due to their relevance in thin-film transistor (TFTs) technologies [1,2]. In addition, their low-temperature process $\left(\leq 200^{\circ} \mathrm{C}\right)$, transparency, high stability, structural uniformity and compatibility with large-area substrates make them very attractive for commercial applications [3]. The main bottleneck for the commercialization of these devices is the understanding of the density of states (DOS) within the bandgap, which is the key to develop analytical models enabling the design of new circuits.

The simulation of these systems before their achievement is useful to calculate the electrical characteristics through numerically solving semiconductor equations [4], where the device structure, material properties and physical models are used to describe the carrier transport properties and the electronic states [5]. Notably, the electronic properties of these oxide semiconductors are still not completely understood, and the role of tail and deep states within the bandgap in transport properties of oxide TFTs is still under investigation [6]. This motivates the modeling of the DOS and makes this research crucial to reproduce the electrical characteristics of oxide TFTs [7].

In this study, the modeling of the DOS through the fitting of the transfer characteristics of zinc oxide ( $\mathrm{ZnO})$ TFTs and the capacitance-voltage curves in metal-insulator-semiconductor (MIS) capacitors using $\mathrm{ZnO}$ as an active layer is presented. The $\mathrm{ZnO}$ semiconductor devices were fabricated by high-frequency ultrasonic spray pyrolysis on polyethylene terephthalate plastic substrates [8]. We propose an accurate estimation of the DOS through calculations performed in similar field-effect devices of the same dielectric-semiconductor interface, since this interface plays an important role to induce conductive channels in TFTs, as well as in the accumulation and depletion regions of MIS capacitors. 
The results show the agreement existing between the experimental data and the simulated electrical characteristics of $\mathrm{ZnO}$ field-effect devices. In this work, different aspects were considered and discussed to model the DOS.

\section{Experimental}

Figure 1 shows the schematic structures of the fabricated devices. The plastic substrates used were made of commercial ITO-coated PET, purchased from Sigma-Aldrich and used as is. The transparent dielectric consists of a thin film of spin-on glass (SOG). The SOG precursor solution was prepared by $33 \%$ of LSF47 solution in $66 \%$ of LSFD1 diluent, provided by Filmtronics Inc. PA, USA. The SOG solution was deposited onto the ITO/PET substrates by spin-coating at $3000 \mathrm{rpm}$ for $30 \mathrm{~s}$ and cured for $10 \mathrm{~min}$ at $100{ }^{\circ} \mathrm{C}$ and $2 \mathrm{~h}$ at $200{ }^{\circ} \mathrm{C}$, resulting in $85 \mathrm{~nm}$-thick SOG film. For TFTs, $100 \mathrm{~nm}$-thick aluminum ebeam evaporated was patterned as source and drain electrodes, followed by the ultrasonic deposition of $90 \mathrm{~nm}$-thick $\mathrm{ZnO}$. The $\mathrm{ZnO}$ precursor solution was prepared from $0.2 \mathrm{M}$ of zinc acetate (Sigma-Aldrich) diluted in methanol. For MIS capacitors, the same substrate, dielectric film and $\mathrm{ZnO}$ films were used. The top contacts were made of ITO films ultrasonically deposited, using an ITO precursor solution prepared from indium chloride (Sigma-Aldrich) at a molar concentration of $0.3 \mathrm{M}$, and tin chloride (Sigma-Aldrich) diluted in methanol at a molar concentration of $5 \mathrm{wt} \%$.

a)

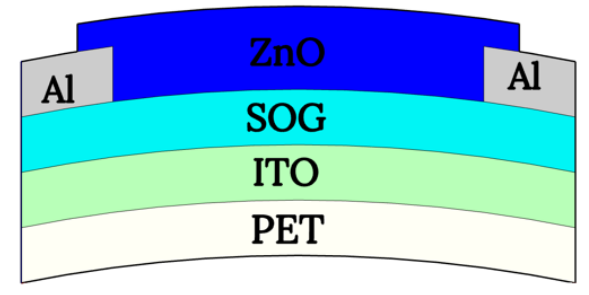

C)

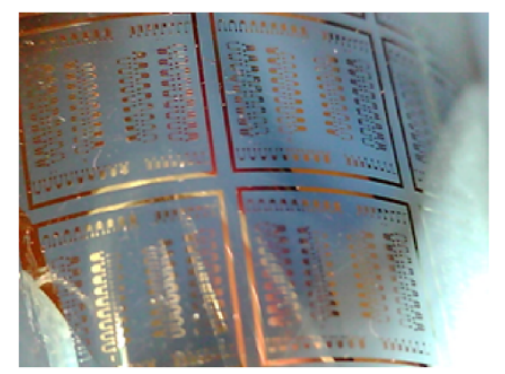

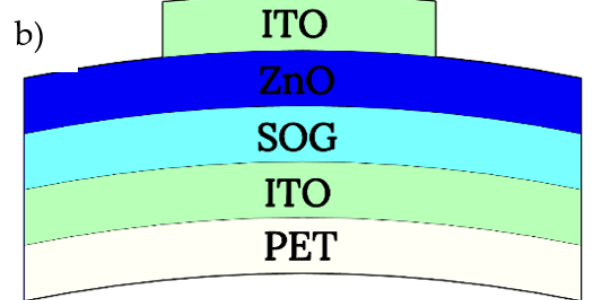

d)

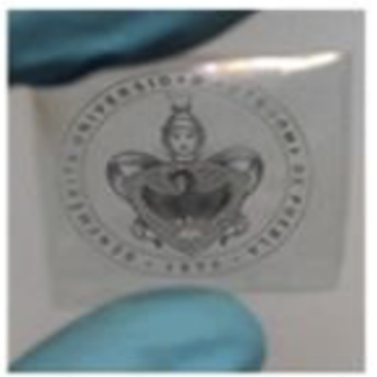

Figure 1. (a) Schematic cross-sectional view of the bottom-gate coplanar TFT, (b) schematic crosssectional view of the MIS capacitor, (c) photograph of ZnO TFTs fabricated onto PET substrates and (d) photograph of MIS capacitor fabricated on PET substrates.

\section{Simulation}

The electrical properties of amorphous materials are strongly related to the DOS [9]. In our approach, it is assumed that the total density of states is composed by acceptor-like states (near the conduction band) and donor-like states (near the valence band), both are composed by the sum of tails' states and deep states. Therefore, a numerical approximation of the DOS distribution, $g(E)$, is given by [10-12]:

$$
g(E)=N_{T A} \exp \left(\frac{E-E_{C}}{W_{T A}}\right)+N_{T D} \exp \left(\frac{E_{v}-E}{W T D}\right)+N_{G A} \exp \left(\frac{E_{G A}-E}{W_{G A}}\right)+N_{G D} \exp \left(\frac{E-E_{G D}}{W_{G D}}\right),
$$

where $N_{T A}$ and $N_{G A}$ are the density of tail-acceptor and deep-acceptor states' distribution respectively, $W_{T A}$ and $W_{G A}$ are the characteristic decay energies of tail-acceptor and deep-acceptor states, $N_{T D}$ and $N_{G D}$ are the density of tail-donor and deep-donor states, $W_{T D}$ and $W_{G D}$ are the characteristic decay energy for donor states and $E_{G A}$ and $E_{G D}$ are 
the peak energy distribution for both acceptor and donor states. The results presented are representative of devices with channel lengths, $\mathrm{L}$, from 10 to $65 \mu \mathrm{m}$ and a channel width, $\mathrm{W}$, of $120 \mu \mathrm{m}$. Discrete trap energy levels were considered in the calculations.

\section{Results and Discussion}

Figure 2 shows the experimental and simulated electron transfer characteristics of the $\mathrm{ZnO}$ TFTs we have achieved on plastic substrates. The parameters used for the DOS calculation are summarized in Table 1 . These values are in the range of the ones reported in the literature for other ZnO TFTs [12-18]. Although it is usually hard to reproduce the subthreshold region of TFTs, since this region is more affected by the DOS, our simulated curve is found to be consistent with the electrical characteristics exhibited below and above the threshold region [19].

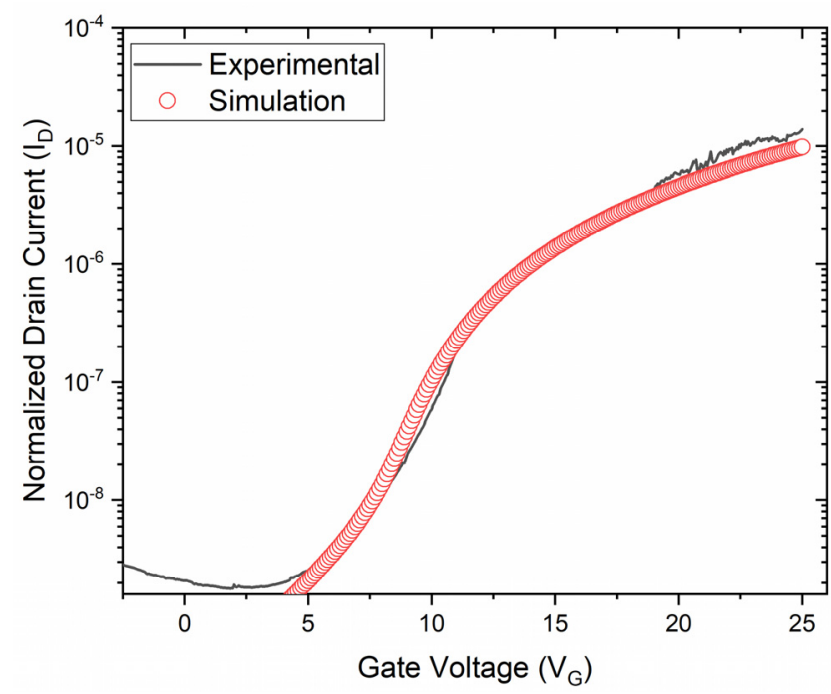

Figure 2. Experimental and simulated transfer characteristics of the ZnO TFTs at $\mathrm{V}_{\mathrm{ds}}=25 \mathrm{~V}$.

On the other hand, since the DOS was modeled in MIS capacitors of the same dielectric-semiconductor interface and $g(E)$ affects the surface potential $\left(\phi_{s}\right)$, the capacitancevoltage curves should depend on $g(E)[20,21]$. The electrons trapped in the localized states are exited and transferred towards the conduction band, which affects the capacitance.

Figure 3 shows the C-V characteristics simulated and measured in MIS capacitors. The experimental data match with the calculations obtained using the DOS parameters presented in Table 1. In this process, the DOS was modeled by fitting the electrical characteristics for both the TFTs and the MIS capacitors. The DOS parameters were adjusted to fit the experimental data. The simulations also accounted for the contact resistance effects, which are known to have an important effect in the electrical characteristics of fieldeffect devices. In Ref. [12], a higher density of acceptor-like states was necessary to compensate the contact resistance contribution. In order to compensate parasitic contributions, the contact resistance was set to $0.1 \mathrm{ohm}-\mathrm{cm}^{2}$ for each contact. 


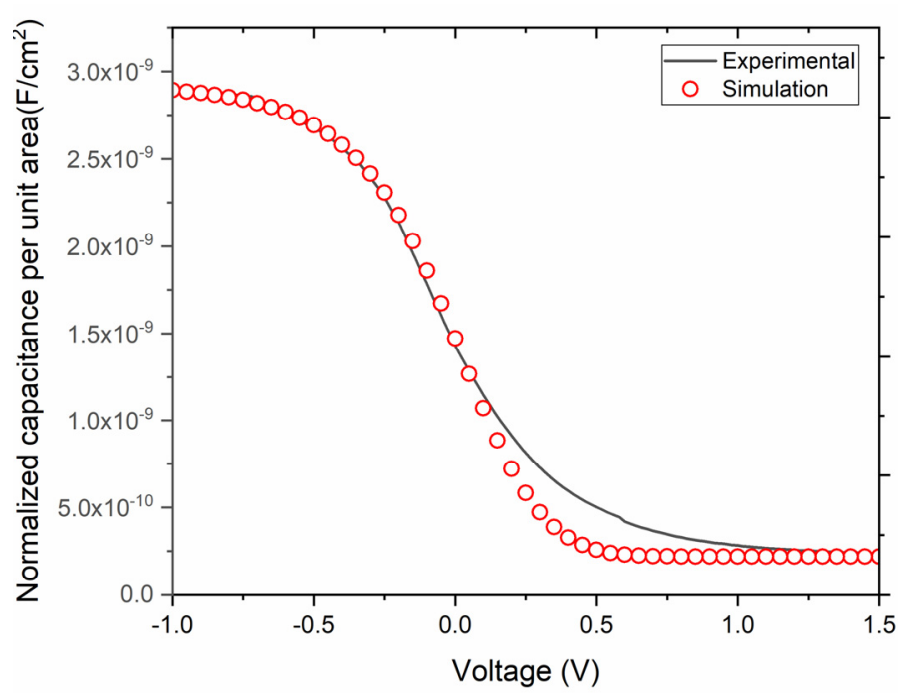

Figure 3. Simulated and experimental C-V characteristics of ZnO MIS capacitors.

Table 1. Main parameters used in the simulations.

\begin{tabular}{ccc}
\hline Parameters & ZnO & Description \\
\hline Eg $(\mathrm{eV})$ & 3.05 & Energy gap \\
$\mathrm{N}_{\mathrm{TA}}\left(\mathrm{cm}^{-3} \mathrm{eV}^{-1}\right)$ & $3.5 \times 10^{20}$ & Density of tail-acceptor states \\
$\mathrm{N}_{\mathrm{TD}}\left(\mathrm{cm}^{-3} \mathrm{eV}^{-1}\right)$ & $4.0 \times 10^{20}$ & Density of tail-donor states \\
$\mathrm{W}_{\mathrm{TD}}(\mathrm{eV})$ & 0.05 & Decay energy of tail-donor states \\
$\mathrm{W}_{\mathrm{TA}}(\mathrm{eV})$ & 0.025 & Decay energy of tail-acceptor states \\
$\mathrm{N}_{\mathrm{GA}}\left(\mathrm{cm}^{-3} \mathrm{eV}^{-1}\right)$ & $1.0 \times 10^{17}$ & Density of deep-acceptor states \\
$\mathrm{N}_{\mathrm{GD}}\left(\mathrm{cm}^{-3} \mathrm{eV}^{-1}\right)$ & $1.5 \times 10^{19}$ & Density of deep-donor states \\
$\mathrm{W}_{\mathrm{GD}}(\mathrm{eV})$ & 0.1 & Decay energy of deep-donor states \\
$\mathrm{W}_{\mathrm{GA}}(\mathrm{eV})$ & 0.05 & Decay energy of deep-acceptor states \\
$\mathrm{E}_{\mathrm{GD}}(\mathrm{eV})$ & 0.1 & Peak energy of deep-donor states \\
$\mathrm{EGA}_{\mathrm{GA}}(\mathrm{eV})$ & 0.35 & Peak energy of deep-acceptor states \\
$\mu_{n}\left(\mathrm{~cm}^{2} / \mathrm{Vs}\right)$ & 15 & Electron band mobility \\
$\mu_{p}\left(\mathrm{~cm}^{2} / \mathrm{Vs}\right)$ & 0.1 & Hole band mobility \\
\hline
\end{tabular}

\section{Conclusions}

In summary, the DOS was modeled to successfully reproduce the experimental electrical characteristics of ZnO TFTs and MIS capacitors. An accurate estimation of the DOS was also obtained by fitting the electrical characteristics in both TFTs and MIS capacitors. The advantage of using physically based simulations is that the DOS of oxide semiconductor films in field-effect devices can be modeled by separating the contribution of each device interface.

Funding: This work was partially funded by the Groupe de Travail Québec-Mexique 2019-2021 MRIF-SRE and the Fondo Sectorial de Investigación para la Educación CONACYT-SEP Ciencia Basica (grant number A1-S-7888).

Data Availability Statement: Data is contained within the article.

Acknowledgments: M. Dominguez thanks Filmtronics Inc. PA, USA, for the supplies provided. O. Obregon would like to thank CONACYT-Mexico for the scholarship awarded.

Conflicts of Interest: The authors declare no conflict of interest. The funders had no role in the design of the study; in the collection, analyses, or interpretation of data; in the writing of the manuscript, or in the decision to publish the results. 


\section{References}

1. Hossain, F.M.; Nishii, J.; Takagi, S.; Ohtomo, A.; Fukumura, T.; Fujioka, H.; Kawasaki, M. Modeling and simulation of polycrystalline $\mathrm{ZnO}$ thin-film transistors. J. Appl. Phys. 2003, 94, 7768-7777.

2. Lu, N.; Jiang, W.; Wu, Q.; Geng, D.; Li, L.; Liu, M. A review for compact model of thin-film transistors (TFTs). Micromachines 2018, 9, 599.

3. Godo, H.; Kawae, D.; Yoshitomi, S.; Sasaki, T.; Ito, S.; Ohara, H.; Yamazaki, S. P-9: Numerical analysis on temperature dependence of characteristics of amorphous In-Ga-Zn-Oxide TFT. In SID Symposium Digest of Technical Papers; Blackwell Publishing Ltd.: Oxford, UK, 2009; Volume 40, pp. 1110-1112.

4. Kim, D.K.; Park, J.; Zhang, X.; Park, J.; Bae, J.H. Numerical Study of Sub-Gap Density of States Dependent Electrical Characteristics in Amorphous In-Ga-Zn-O Thin-Film Transistors. Electronics 2020, 9, 1652.

5. Abe, K.; Ota, K.; Kuwagaki, T. Device Modeling of Oxide Semiconductor TFTs. In Proceedings of the 2020 27th International Workshop on Active-Matrix Flatpanel Displays and Devices (AM-FPD), Kyoto, Japan, 1-4 September 2020; pp. 137-140.

6. Zhang, A.; Zhao, X.-R.; Duan, L.-B.; Liu, J.-M.; Zhao, J.-L. Numerical study on the dependence of ZnO thin-film transistor characteristics on grain boundary position. Chin. Phys. B 2011, 20, 57201.

7. Dosev, D.; Inıguez, B.; Marsal, L.F.; Pallares, J.; Ytterdal, T. Device simulations of nanocrystalline silicon thin-film transistors. Solid-State Electron. 2003, 47, 1917-1920.

8. Obregón, O.; Luna-Lopez, J.A.; Dominguez, M. Transistores de Película Delgada Basados en Oxido de Zinc por Spray Pyrolysis Ultrasónico de Alta Frecuencia a Baja Temperatura. Rev. Mex. Física 2021, accepted.

9. Park, J.H.; Lee, S.; Jeon, K.; Kim, S.; Kim, S.; Park, J.; Kim, D.H. Density of states-based DC I-V model of amorphous galliumindium-zinc-oxide thin-film transistors. IEEE Electron Device Lett. 2009, 30, 1069-1071.

10. ATLAS User's Manual; Silvaco International: Santa Clara, CA, USA, 2002.

11. Chen, W.F.; Qin, G.M.; Zhou, L.; Wu, W.J.; Zou, J.H.; Xu, M.; Peng, J.B. A physics-based model of flat-band capacitance for metal oxide thin-film transistors. AIP Adv. 2018, 8, 65319.

12. Dominguez, M.A.; Alcantara, S.; Soto, S. Physically-based simulation of zinc oxide thin-film transistors: Contact resistance contribution on density of states. Solid-State Electron. 2016, 120, 41-46.

13. Dominguez, M.A.; Pau, J.L.; Redondo-Cubero, A. Unusual ambipolar behavior in zinc nitride thin-film transistors on plastic substrates. Semicond. Sci. Technol. 2019, 34, 55002.

14. Gupta, D.; Jang, J.; Nayak, P.K.; Hong, Y. Investigating the environmental stability of Li-doped ZnO based thin film transistors by two dimensional numerical simulations. In Proceedings of the 2010 23rd Annual Meeting of the IEEE Photonics Society, Denver, CO, USA, 7-11 November 2010; pp. 309-310.

15. Saha, J.K.; Billah, M.M.; Bukke, R.N.; Kim, Y.G.; Mude, N.N.; Siddik, A.B.; Jang, J. Highly stable, nanocrystalline, ZnO thin-film transistor by spray pyrolysis using High-K dielectric. IEEE Trans. Electron Devices 2020, 67, 1021-1026.

16. Ditshego, N.M.; Sultan, S.M. 3D Simulation Investigating ZnO NWFET Characteristics. J. Nano Res. 2019, 58, 40-48.

17. Torricelli, F.; Meijboom, J.R.; Smits, E.; Tripathi, A.K.; Ferroni, M.; Federici, S.; Cantatore, E. Transport physics and device modeling of zinc oxide thin-film transistors part I: Long-channel devices. IEEE Trans. Electron Devices 2011, 58, $2610-2619$.

18. Fung, T.C.; Chuang, C.S.; Chen, C.; Abe, K.; Cottle, R.; Townsend, M.; Kanicki, J. Two-dimensional numerical simulation of radio frequency sputter amorphous In-Ga-Zn-O thin-film transistors. J. Appl. Phys. 2009, 106, 84511.

19. Dominguez, M.; Rosales, P.; Torres, A.; Moreno, M.; Molina, J.; De la Hidalga, F.; Calleja, W. Ambipolar a-SiGe: H thin-film transistors fabricated at $200^{\circ}$ C. J. Non-Cryst. Solids 2012, 358, 2340-2343.

20. Park, J.H.; Jeon, K.; Lee, S.; Kim, S.; Kim, S.; Song, I.; Kim, D.H. Extraction of density of states in amorphous GaInZnO thin-film transistors by combining an optical charge pumping and capacitance-voltage characteristics. IEEE Electron Device Lett. 2008, 29, 1292-1295.

21. Jeon, K.; Kim, C.; Song, I.; Park, J.; Kim, S.; Kim, S.; Kim, D.H. Modeling of amorphous InGaZnO thin-film transistors based on the density of states extracted from the optical response of capacitance-voltage characteristics. Appl. Phys. Lett. 2008, $93,182102$. 